\title{
Workshop report: Launching of the revised reproductive health policy guidelines and standards
}

Division of Primary Health Care, Kenya Ministry of Health

Follow this and additional works at: https://knowledgecommons.popcouncil.org/departments_sbsr-rh

Part of the Demography, Population, and Ecology Commons, Health Services Research Commons, International Public Health Commons, and the Women's Health Commons How does access to this work benefit you? Let us know!

\section{Recommended Citation}

"Workshop report: Launching of the revised reproductive health policy guidelines and standards." Division of Primary Health Care, Ministry of Health, Kenya, 1998. 


\section{Workshop Report}

\section{Launching of the Revised Reproductive Health Policy Guidelines and Standards

$$
23-25 \text { February } 1998
$$

\section{Division of Primary Health Care, Ministry of Health Kenya}

With support from:

Population Council (Africa Operations Research and Technical Assistance Project)

United States Agency for International Development (USAID)

Department for International Development (DFID) 


\section{Background and objectives:}

The Government of Kenya has recently (June 1997) revised its Policy Guidelines and Standards for family planning and other reproductive health services to encourage service providers to undertake a more comprehensiveapproach to service delivery. These Guidelines and Standards include a number of revised and new recommendations for service providers relating to:

- the provision of family planning methods;

- other general reproductive health issues such as services for adolescents, infertility, breast-feeding and cervical cancer screening;

- safe motherhood, including post-abortion care;

- the integration of STI/HIV/AIDS control into the MCH/FP program.

For many service providers these recommendations will require a re-orientation of how they currently provide services. Because of this, the Division of Primary Health Care (DPHC) would like to ensure that the guidelines are presented to providers with a full explanation of their programmatic implications. Some of the recommendations, especially those relating to the integration of STI/HIV/AIDS services into $\mathrm{MCH} / \mathrm{FP}$ services, and to safe motherhood, include some new practices and procedures. Consequently, the DPHC wanted to not only present the recommendations themselves but also to review how they can best be implemented through reference to empirical evidence from programs which have already started implementing a reproductive health approach. A number of research studies have been conducted in Kenya and elsewhere in the region which provide data pertinent to many of these recommendations, and the DPHC used the results from these studies to provide a framework within which the guidelines were presented and discussed during this workshop.

For example, much has been learned recently about how an integrated approach to screening and managing $\mathrm{MCH} / \mathrm{FP}$ clients for STIs including HIV is being implemented in several countries in east and southern Africa, including Kenya. The Africa OR/TA Project II had documented and synthesized these lessons, many of which are directly relevant to the new DPHC guidelines. In addition, the DPHC, with support from the Department for International Development (DfID), had compiled a review of safe motherhood issues in Kenya based on a number of research studies conducted in the country on maternal mortality and morbidity.

Therefore, the DPHC, in collaboration with the Africa OR/TA Project of the Population Council with support from USAID and DfID organized a workshop for program managers with the following objectives: 
1. To present the policy guidelines and standards for reproductive health / family planning services to senior program managers in Kenya.

2. To highlight the key findings arising from research studies that are pertinent to guiding implementation of the revised service delivery guidelines.

3. To review the recommendations in the guidelines with reference to empirical evidence from research studies so that managers can understand the programmatic implications of their implementation.

4. To identify the next steps in disseminating these guidelines throughout Kenya.

\section{Workshop organization:}

The DPHC took the lead role in organizing the workshop by planning the agenda, inviting the participants and speakers, and hosting the workshop. The Africa OR/TA Project II provided logistical support by arranging the venue for the meeting and accommodation for the participants, and by coordinating the resource contributions from DfID and USAID.

During the workshop, held at the Hilton hotel in Nairobi $23^{\text {rd }}-25^{\text {th }}$ February 1998, the DPHC presented the new Policy Guidelines and Standards document. The recommendations in the document were reviewed and their rationale explained in detail. Wherever relevant, results from selected research studies were presented to provide participants with an empirical basis on which to discuss implementation of the recommendations. The participants worked in groups structured along Provincial Health Management Teams (PHMT) represented at the workshop and plenary sessions were used to discuss recommendations from the working groups. The workshop was attended by senior managers and reproductive health supervisors from the national, provincial and municipal levels of the Ministry of Health, and of the National AIDS Control Program (NASCOP); a full list of participants is given in the Appendix. This workshop was seen by the DPHC as the first step in disseminating the guidelines to all service providers in Kenya. As one outcome of the workshop, participants prepared plans of how best to disseminate the guidelines within their own provincial or municipal programs. 


\section{Key Issues and Recommendations arising from the workshop}

Following presentation of the revised Family Planning Guidelines and Guidelines on other Reproductive Health issues, the participants raised the following issues and recommendations on the various sections of the guidelines.

\section{Infection Prevention}

The participants noted that infection control is key to the provision of good quality reproductive health services using an integrated approach. They observed that the following practices and actions are essential for the successful practice of infection control and should be implemented immediately.

- Stop recycling used gloves in health facilities

- Improving supplies to strengthen decontamination, disposal of sharps, proper sterilization and

- Reducing relatives who roam around the hospitals.

\section{Provision of Norplant ${ }^{\circledR}$ contraceptive}

The participants noted that there was a high incidence of Norplant ${ }^{\circledR}$ removals attributed to continuous bleeding in the second year of use. They also noted that a large number of removals were due to husband pressure. The following recommendations were made;

- that this issue should be investigated and results communicated to the service providers.

- that service providers should overcome this by good counseling skills involving the couples and not individual female clients.

The workshop was informed that in its attempt to make Norplant more widely available to clients a feasibility study to evaluate nurses' ability to provide Norplant services was undertaken by the DPHC and recommendations from the study will be available soon.

\section{Post-abortion care using MVA}

The workshop was informed that pilot studies using MVA to manage post-abortion complications have been completed and the services will be expanded to cover 30 district hospitals in a scaling-up exercise.

The participants were also informed that clinical officers would be trained to provide this service where there are insufficient medical officers. This decision was the result of a research study that had shown that clinical officers could provide these services when properly trained. 
emphasized the need for counseling about the procedure. Many practitioners who were using paracervical block reported that the procedure was effective in controlling pain during the MVA procedure.

- The participants recommended that where this was not possible other pain relievers could and should be used.

Many participants felt that the situation in Kenya has changed and the demand for abortion services has increased. Many women were dying or getting permanently disabled due to complications resulting from abortion clandestinely induced by untrained individuals in unhygienic circumstances.

- They recommended that there should be advocacy for change of abortion laws in line with the current situation in Kenya.

\section{Safe Motherhood}

Participants noted that the situation in Kenya has worsened. Maternal morbidity and mortality rates have increased. They observed that labor management, referralsystem and facility preparedness were poor in most provinces and improvements in these areas should be considered as priority areas in any safe motherhood initiatives.

- The participants recommended that managers of health programs and the community through their opinion leaders need to work together to plan and improve the available health services for the successful implementation of any safe motherhood initiative.

The participants also noted that a lack of adequate resources, supplies and effective and independent management structures were frustrating their efforts to provide good quality reproductive health services.

- Therefore, the participants recommended that Hospital boards should be allowed and facilitated to work independently and decide on how to raise more revenue and how to disburse and utilize the revenue raised for improving the quality of services in their facilities.

- They also recommended that the $\mathrm{MOH}$ should train or employ personnel trained in financial management or train those already heading the institutions to facilitate better financial management.

\section{STI/HIV services}

The participants noted that acceptance of condom use is low in most of the provinces especially in those programs where male condoms are given to female clients to pass onto their male partners despite the awareness campaigns. They also observed that despite the low acceptance and use of condoms, safe sex is not emphasized in the revised guidelines. 
- They recommended that the guidelines should be reviewed in order to include and emphasize safe sex practices in order to empower service providers to promote condom use within their programs

- In addition the participants recommended that politicians and other opinion leaders in communities should be sensitized and empowered with skills to educate people on condom use.

The participants also observed that HIV testing, vertical transmission and STI integration are not mentioned in the guidelines.

- They recommended that although they are not mentioned and emphasized in the guidelines, they should be addressed in the regional dissemination.

- They also recommended that there is a need to reduce the gap in integration of $\mathrm{MCH} / \mathrm{FP} / \mathrm{STI}$ service provision area.

- In additionthey recommended that syndromic managementof STI should be provided by the FP service providers.

\section{PLANS OF ACTION DEVELOPED BY PROVINCIAL TEAMS}

Each provincial team was requested to develop a plan of action that they would use to disseminate the guidelines in their provinces. The plan of action should identify the action to be taken, who is going to be responsible for initiating and leading the action and when the action is to be undertaken. In addition they were asked to identify key issues they had learned from the guidelines and other discussions at the workshop that needed to be communicate to service providers within their province. 


\section{Appendices}

\section{Agenda for Workshop to Launch the \\ Revised Reproductive Health Policy Guidelines and Standards: $23^{\text {rd }}-25^{\text {th }}$ February, 1998}

Day $1 \quad$ Monday, February $23^{\text {rd }} 1998$

8.30 - 9.00 Overview of workshop and opening remarks - Dr P. Gaturuku

9.00 - 9.15 Welcome: Director, Medical Services

Representative, USAID

Representative, DFID

9.15 - 10.45 Presentation of the revised Family Planning Guidelines - Dr Hassan

10.45 - 11.00 BREAK

11.00 - 12.00 Presentations of Guidelines on Reproductive Health Issues - Dr Achola

$12.00-1.00$ Discussion

$1.00-2.00 \quad$ LUNCH

$2.00-2.45$ General Status of Safe Motherhood in Kenya - Dr Makumi

2.45 - 3.30 Report on Review of Safe Motherhood in Kenya - Mrs Ouda

$3.30-3.45 \quad$ BREAK

3.45 - 4.30 Discussion - Dr Othigo/Dr Oyoo (Moderator)

$4.30-5.00$ The Way Forward - Dr Hassan

$5.30-6.30 \quad$ Cocktail 


\section{Day 2 (Tuesday, February $24^{\text {th }} 1998$ )}

8.30 - $9.00 \quad$ Introduction to Postabortion Care - Ms Aloo-Obungu/Dr Orero

9.00 - 9.30 Presentation of Policy Guidelines on Postabortion Care - Dr Achola

9.30 - 10.00 Experiences with Implementing Postabortion Care - Dr Ndede

10.00 - 10.30 Discussion - Dr Makumi (Moderator)

10.30 - 11.00 Introduction to MOH policy papers on STD/AIDS - Dr Hagembe

11.00 - 11.30 The Rationale for, and Advantages and Disadvantages of Integration - Dr Sangvi

$12.00-12.30$ Status of STIs including HIV/AIDS in Kenya - Dr Mboya

$12.30-1.00$ Presentation of Policy Guidelines on Integration of STI/HIV Services - Dr Hagembe

$1.00-2.00 \quad$ LUNCH

$2.00-2.15$ Case Study of Nakuru Municipal Council - Mr. Kariba

2.15 - 2.30 Case Study of Mkomani Medical Society - Dr Onyango

2.30 - 3.00 Lessons Learned on Implementing STI Preventive Practices in MCH/FP Clinics - Dr Askew

$3.00-3.30$ Discussion of Experiences in Kenya - Dr Kariuki (Moderator)

\section{$3.30-3.45 \quad$ BREAK}

3.45 - 4.15 Current Guidelines for Syndromic Diagnosis and Management of STIs in Kenya - Dr Mohammed

4.15 - 4.45 Advantages and Disadvantages of Integrating STI/HIV Risk Assessment Procedures in MCH/FP Clinics - Dr Welsh

4.45 - 5.15 Lessons Learned on Screening, Diagnosis and Treatment of STIs in MCH/FP Clinics - Dr Maggwa

5.15 - 6.00 Discussion - Dr Hassan (Moderator) 
Day 3 (Wednesday, February $25^{\text {th }}$ 1998)

8.30 - $9.00 \quad$ Plenary Review of Key Issues Raised - Dr Hassan

9.00-10.30 Small Group Meetings to develop recommendations for dissemination and implementation of guidelines at provincial and district levels

10.30 - 11.00 BREAK

$11.00-12.00$ Report back by group rapporteurs

12.00 - 12.15 Closing Remarks - Dr Hassan

$12.15-1.00 \quad$ Lunch and Departure 


\section{LIST OF PARTICIPANTS BY PROVINCE}

TITLE/ORGANIZATION

\section{Central Province}

Jedidah W Ndegwa

Lucy W Njenga

Dr Sainepu

\section{Coast Province}

Flora Ali

Dr Joel Othigo

Dr MM Solomon

Mrs Winnie Mjambu

Dr JA Onyango

\section{Eastern Province}

Bibiana M Mulwa

Dr C Olango Onudi

Dr DW Kapanga

PT Murianki

Peter Kariuki Gitahi

\section{Nairobi Province}

Dr Achola-Ominde

Anne K Njeru

Charity N Ndwiga

EW Kwinga

Esther Kiragu

Grace Kihindas

Isaac K Njuguna

Jane N Asila

Jennifer O Omufwoko

Joyce K Mbui

MW Ngure

Margaret Makumi

Margaret Mbugua

Dr Mary Wangaiu

Melisah Mulimba

Nancy Waweru

Dr Peter Gaturuku

RW Kamau
Doctor

PMO's Central

FP/Trainer

$\mathrm{CPGH}$

Malindi District Hospital

$\mathrm{ACNO}$

Mkomani Clinic
PMO

Machakos Hospital

SNO

Nursing Officer

\section{ADDRESSES}

Box 27 Nyeri

Box 110 Nyeri

Box 27 Nyeri

Box $90231 \mathrm{Msa}$

Box 91208 Msa

Box 267 Malindi

Box 90233 Msa

Box 41075 Msa
Box 19 Machakos

Box 273 Embu

Box $19645 \mathrm{Nrb}$

Box 273 Embu

Box 66 Nanyuki

\begin{tabular}{|c|c|}
\hline MCH/FP Manager & Box 43319 \\
\hline Trainer & Box 43319 \\
\hline Trainer & Box 34349 \\
\hline $\mathrm{MOH}$ & Box 30016 \\
\hline PMO & Box 34349 \\
\hline DPHC & Box 43319 \\
\hline DHE & Box 30562 \\
\hline DPHC & Box 43319 \\
\hline Trainer & Box 43319 \\
\hline Program Assistant & Box 57964 \\
\hline $\mathrm{MOH}$ & Box 30016 \\
\hline MOH/DPHC & Box 43319 \\
\hline DPHC & Box 43319 \\
\hline PMO & Box 34349 \\
\hline DPHC & Box 43319 \\
\hline DPHC & Box 43319 \\
\hline DDMS & Box 20781 \\
\hline KMTC & Box 30195 \\
\hline
\end{tabular}


Rita Mureithi

VW Gichuru

\section{North Eastern Province}

Joseph G. Wangundu

Nyanza Province

Dr Chris Oyoo

Clementine A Gnoswar

DO Odhiambo

DO Katieno

Rachel Ondeche

Samwel Kiragori

\section{Rift Valley}

Dr FK Sawe

Dr FO Ndede

Dr Kenneth L Chebet

Mary Oyoo

Scholastica Karanja

Simon K. Wainaina

\section{Western Province}

Roseline Oboya

Dr NP Rupavi

Veronica Okoth
Nursing Officer

SNO
Box 53271

Box 30108

Box 40 Garissa

Box 849 Ksm

Box $849 \mathrm{Ksm}$

Box $849 \mathrm{Ksm}$

Box $52 \mathrm{H} /$ Bay

Box $48 \mathrm{Ksm}$

Box $92 \mathrm{Ksm}$
Gynaecologist

PMO

Nursing Officer

Nurse

Nursing Officer
Box 11 Kericho

Box 71 Nakuru

Box 2060 Nakuru

Box 11 Kericho

Box 124 Nakuru

Box 141 Naivasha

\section{Cooperating Agencies and other institutions}

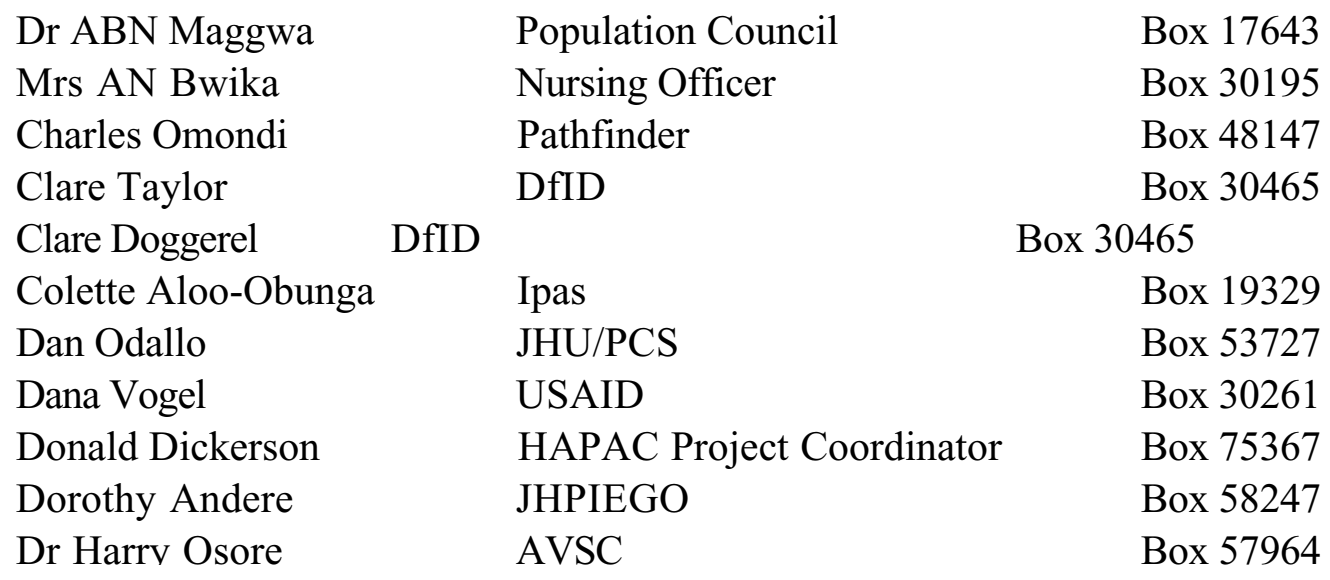

Box 87 Busia

Box 15 Kakamega

Box 359 Kakamega
MOH's

OBGYN

PSNO 
Ian Askew

Julie Solo

Martha W Warratho

Naomi Rutenberg

Dr SO Orero

Peris W Mwiriuki

Dr Stella Abwao

Bertha M French
Population Council

Population Council

Marie Stopes

Population Council

Ipas consultant

UNFPA/RH Project

PATH

Ipas
Box 17643

Box 17643

Box 59329

Box 17643

Box 62323

Box 43319

Box 76634

Carrboro, USA 